\title{
Silylium ion Migration Dominated Hydroamidation of Siloxy-alkynes
}

\author{
HengdingWang1,2, Ling Jiang1,2, HongjunFan ${ }^{1,2 *}$. \\ ${ }^{1}$ State Key Laboratory of Molecular Reaction Dynamics, Dalian National Laboratory for Clean Energy, Dalian Institute of \\ Chemical Physics, Chinese Academy of Sciences, Dalian 116023, China \\ ${ }^{2}$ University of Chinese Academy of Sciences, Beijing 100864, China.
}

\begin{abstract}
Intermolecular hydroamidation of internal alkynes has been a long-standing challenge, one of the most successful examples so far is silver-catalyzed hydroamidation of siloxyalkynes for which meet the standards of atom economic and mild reaction conditions of ideal hydroamidation. However, the mechanism of this reaction remains controversy. Using density function theory (DFT), we revealed that the reaction takes place through a silylium ion migration mediated hydroamidation (SMH) pathway. The SMH pathway goes through two steps, the first step is $\mathrm{Ag}+$ promoted proton and silylium ion exchange between siloxyalkynes and amide, leading to ketene and silyl-imines, the second step is Ag+ catalyzed nucleophilic addition between ketene and silyl-imines, following with a silylium ion migration afford the final product. In this reaction, Ag+ activate the siloxy-alkyne into
\end{abstract}

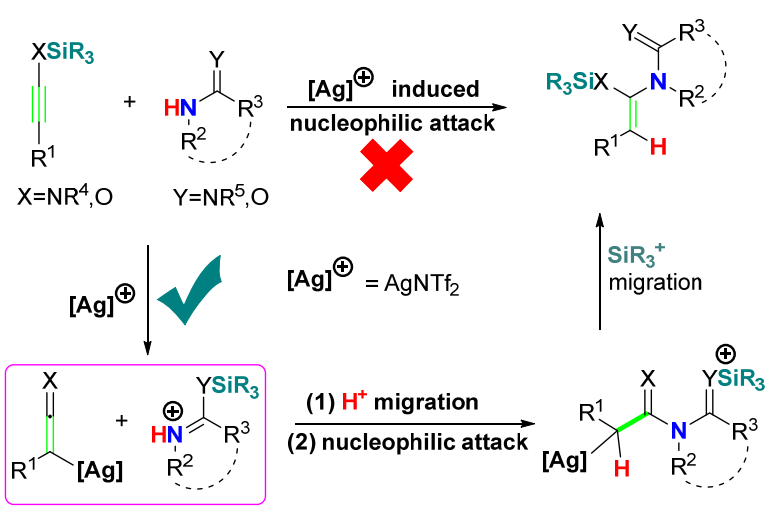
silylium ion and silver-ketene through $p$ - $\pi$ conjugate effect, the silylium ion then act as catalyst. According to our calculation, the scopes of alkynes in this reaction may be extend to silyl-substituted ynamines or silyl-substituted ynamides, and the scopes of amide maybe expanded into $p-\pi$ conjugate system such as diazoles, diazepines and so on. Our calculations also reveal a concise way to construct substituted enamides through Ag+ catalyzed nucleophilic addition between ketenes (or ketene imines) and silyl-substituted $p$ - $\pi$ conjugate system such as silyl-imines, silyl-diazoles.

\section{Introduction}

Hydroamidations have attracted very attentions for it's an atomic-economy way to construct enamides ${ }^{1-9}$. Further, the substrates of this reaction are easily-accessible. Hydroamidations are not spontaneous mainly due to the relatively high barrier of nucleophilic process ${ }^{10}$. Lewis-acid or transition metals are often used to catalyze this reaction. Significant progresses have been made in catalyzed hydroamidation and high levels of chemo-, regio-, and stereo- selectivity have been reported ${ }^{4}, 11-12$. However, current reported successful examples are mainly center on intramolecular hydroamidation ${ }^{13-16}$ or hydroamidation involving terminal alkynes, ${ }^{9}$, and relatively high temperature is required in the most case.

To date, the catalytic variant remains rather limited, especially in hydroamidation of internal alkynes ${ }^{18-20}$. To the best of our knowledge, there were only two hydroamidation reactions of internal alkyne which meet the requirements of atomic economic of ideal hydroamidation ${ }^{18-19}$. Indisputably, make clear the mechanisms of these reactions are very important, for which can provide direct insights to broaden substrate scope and improve efficiency of such reaction.

In 2016, Cui et al. reported first example of hydroamidation of phenyl-substituted alkyne with $\mathrm{Ru}(\mathrm{II})$ as catalyst $\mathrm{t}^{19}$. The reaction proceed under relatively high temperature $\left(90^{\circ} \mathrm{C}\right)$ and the substrates scope of amides is very limited, only the N1-benzyl-N2,N2- diisopropyloxalamide and its analogs are suitable for this reaction.

In 2006 Kozmin et al. reported the first example of hydroamidation of internal alkynes ${ }^{18}$. They found that $\mathrm{AgNTf}_{2}$ can promotes the addition of second-amides or carbamates to the triple-bond of siloxy-alkyne successfully in the room temperature within 30 min (Scheme 1a). In this reaction, the $E$-configured Markovnikov product is exclusively obtained. The authors also found that the commonly used ynamides and simple internal alkynes are inactive in the same condition. Based on deuterium label experiment, the author proposed a silver induced nucleophilic addition mechanism (NUA mechanism, Scheme 1b). In this mechanism, the silver(I) coordinated with siloxy-alkyne $\mathbf{1}$ to form $\pi$-complex INTA, the amide $\mathbf{2}$ then nucleophilic attack the siloxy-alkyne $\mathbf{1}$ to form $Z$-INTB. Proton transfer of $\boldsymbol{Z}$-INTB lead to final product $\boldsymbol{Z}$-3. The nucleophilic attack step is thought to be rate determine step (RDS).

The mechanism complies with some experimental observation, but does not explain why electron-richer ynamides are nonreactive in the same condition, it should be more reactive if this reaction proceed through silver(I) induced nucleophilic attack process ${ }^{21-23}$. Further, the transition metal induced nucleophilic reaction favors take place at trans-direction of metal atom due to the $\beta$-effect ${ }^{24}$. 
Scheme 1. Silver(I) catalyzed hydroamidation reported by Kozmin et al. (a)<smiles>[R]C#C[C-]OCC</smiles>

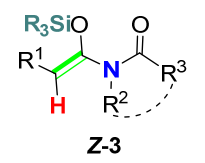

Z-3 (b)

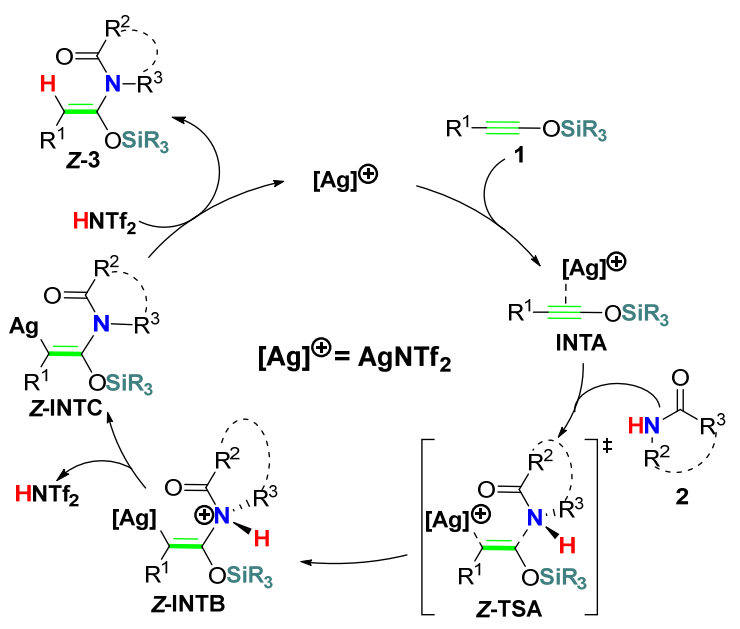

The aims of this study are to find a more reasonable mechanism of this pioneer work to understand, the reactivity, as well as the origins of chemo and regioselectivity of this reaction. The potential substrates scopes of this reaction have been discussed based on our proposed mechanism.

\section{Model reaction}

Methyl substituted siloxy-alkyne 1a and carbamate 2a was choose as model reaction, $\operatorname{AgNTf}_{2}$ was choose as catalyst. dichloromethane (DCM, $\varepsilon=8.93$ ) was choose as solvent.

\section{Computational details}

Density function calculations (DFT) were performed with the Gaussian 16 program package ${ }^{25}$. The structures of TS1 and INT1 were optimized in solvent under $\omega \mathrm{b} 97 \mathrm{xd}-$ SMD/def2-SVP26-27 level of theory for electron static effect and steric hindrance of triisopropylsilyl (TIPS) group make it very hard to load these five coordinated structures in the gas phase ${ }^{22}$. The single point energy of TS1 and INT1 was corrected at $\omega \mathrm{b} 97 \mathrm{xd}$ (gas) /def2tzvpp level of theory, so:

$G_{\text {deftzvpp }}^{\text {sol }}=G_{\text {def2svp }}^{\text {sol }}-E_{\text {def2svp }}^{\text {gas }}+E_{\text {def2tzvpp }}^{\text {gas }}$

The barrier of formation TS1 And INT1 is evaluated with:

$\Delta G_{\text {deftzvpp }}^{\text {sol }}=G_{\text {deftzvpp }}^{\text {sol }}(1)-G_{\text {deftzvpp }}^{\text {sol }}(0)$

$G_{\text {deftzvpp }}^{\text {sol }}(1)$ refers corrected Gibbs free energy of TS1 or
INT1, $G_{\text {defztzvpp }}^{\text {sol }}(0)$ refers to corrected Gibbs free energy of reference point 1a, $\mathbf{2 a}$ and $\operatorname{AgNTf}_{2}$.

The other structural optimizations were performed under $\omega \mathrm{b} 97 \mathrm{xd}$ (gas)/def2-SVP level of theory. Single point energy was calculated at $\omega \mathrm{b} 97 \mathrm{xd} / \mathrm{def} 2 \mathrm{tzvpp}$ level of theory. Solvation calculations were carried out with SMD solvation model at $\omega \mathrm{b} 97 \mathrm{xd} /$ def2-SVP level of theory with dichloromethane (DCM, $\varepsilon=8.93$ ) as solvent. So, in this case, corrected Gibbs energy is:

$$
\begin{gathered}
G_{\text {deft tzvpp }}^{\text {corr-sol }}=G_{\text {def2svp }}^{\text {gas }}-E_{\text {def } 2 s v p}^{g a s}+E_{\text {def2tzvpp }}^{\text {gas }}+E_{\text {def } 2 s v p}^{\text {sol }} \\
-E_{\text {def } 2 s v p}^{\text {gas }}
\end{gathered}
$$

The barrier is evaluated with:

$$
\Delta G_{\text {deftzvpp }}^{\text {corr-sol }}(S M D)=G_{\text {deftzvpp }}^{\text {corr-sol }}(1)-G_{\text {deftzvpp }}^{\text {corr-sol }}(0)
$$

Our previous work has shown that this scheme is well suitable for evaluate reaction barrier of such system ${ }^{22}$. Actually, $\Delta G_{\text {deftztopp }}^{\text {corr-sol }}(S M D)$ is a good approximation of $\Delta G_{\text {def2tzvpp }}^{\text {sol }}$ Vibrational frequency calculations were carried out at same level of theory as geometries optimization to verify that the optimized geometries are energy minimum or transition state and to provide thermal corrections for Gibbs free energies and enthalpies at $298.15 \mathrm{~K}$ in $1 \mathrm{~atm}$. IRC calculation was performed for the key transition states to verify that the optimized transition states lead to correct structures $^{28}$. Optimized geometries were rendered with CYLView $^{29}$. The NCI analysis ${ }^{30}$ was carried out with Multiwfn ${ }^{31}$ and rendered with VMD ${ }^{32}$. The electrophilicity $\omega$ index and nucleophilicity $\mathrm{N}$ index is calculated with $^{33}$ $\omega \mathrm{b} 97 \mathrm{xd} / \mathrm{def} 2 \mathrm{svp}$ level of theory.

$$
\begin{aligned}
& \omega=\frac{\left(E_{\text {номо }}+E_{\text {LUMO }}\right)^{2}}{8\left(E_{\text {номо }}-E_{\text {LUMO }}\right)} \\
& N=\left[E_{\text {номо }}(\text { Nucleophile })\right. \\
& \text { - } E_{\text {LUмо }} \text { (Tetracyanoethelene)] }
\end{aligned}
$$

\section{Results and Discussion}

\subsection{Nucleophilic attack at carbon atom (NUA mechanism).}

We evaluate the author proposed NUA mechanism (Figure 1). At beginning of the reaction, coordination of siloxy-alkynes 1a with the $\mathrm{AgNTf}_{2}$ is exergonic by $10.1 \mathrm{kcal} / \mathrm{mol}$ (Figure 1a). AgNTf 2 coordinate with triple bond of 1a, makes 1a susceptible to nucleophilic attack. There are three possible sites to attack 1a, which is $\alpha$-C, $\beta$-C (Figure 1a) and silicon atom. As for the nucleophilic attack of the two $s p$-hybridized carbon atoms, nucleophilic at $\alpha$-C position is much more facile due to $p$ - $\pi$ conjugate effect ${ }^{22}$. So, we only consider nucleophilic attack of the $\alpha$-C position. There are two directions of nucleophilic attack at $\alpha$-C 
(a)

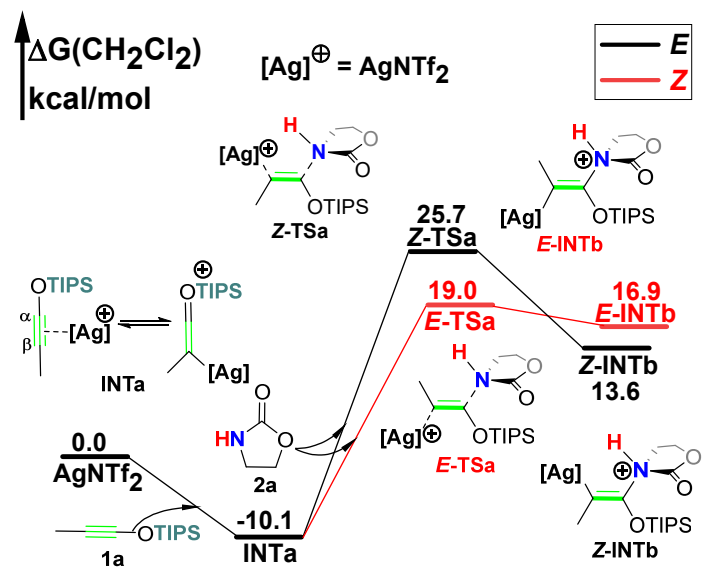

(b)
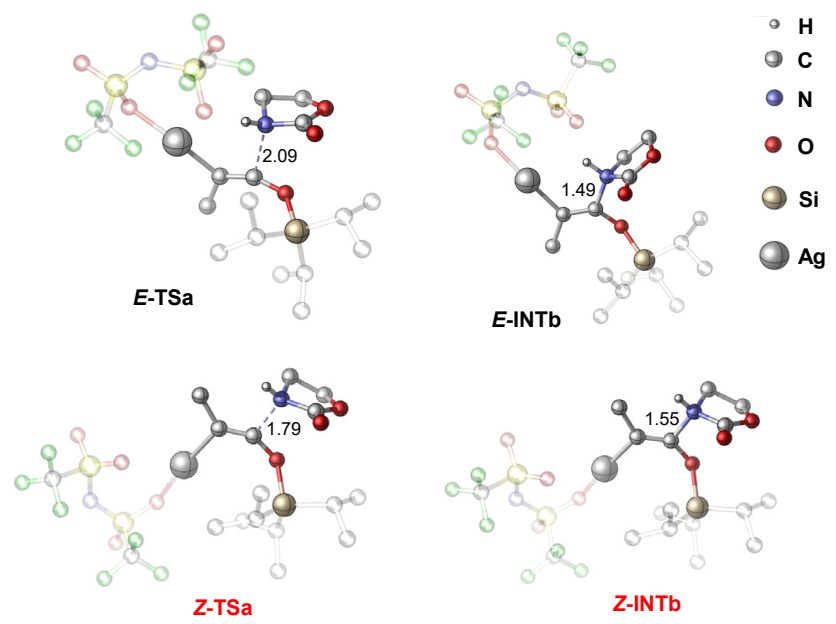

Figure 1. Ag+ induced nucleophilic attack mechanism (NUA mechanism), Gibbs energies are in kcal/mol. a. Gibbs free energy profile. b. Optimized geometries. The hydrogen atom was omitted, the isopropyl of triisopropylsilyl (TIPS) group and $\mathrm{NTf}_{2}-$ anion was set to transparent for clarity.

position, if nucleophilic attack take place at the $\operatorname{AgNTf}_{2}$ side, cis-addition product $\boldsymbol{Z}$-3a will be obtained; otherwise, trans-addition product $\boldsymbol{E}$-3a will be formed. Our calculation shows that the nucleophilic attack of 2 a prefers take place at opposite side of $\mathrm{AgNTf}_{2}$ which lead to trans-conformation product $\boldsymbol{E}$-3a, the main cause of the trans-selectivity is the trans- $\beta$ effect ${ }^{24}$. The $\mathrm{C}-\mathrm{N}$ formation leading to $\boldsymbol{Z}-\mathbf{3 a}$ is energetically highly disfavored with a barrier (Z-TSa) $35.8 \mathrm{kcal} / \mathrm{mol}$, implies that the commonly accepted NUA pathway is disfavored.

\subsection{Silylium ion migration dominated hydroamidation (SMH) mechanism.}

The nucleophilic attack at silicon atom of siloxy-alkyne is often overlooked for the large size of TIPS group. However this process is quite easy in somecases ${ }^{22}$. Enlighted by our previous work $^{22}$, we proposed a silylium ion migration dominated hydroamidation (SMH) mechanism for this reaction (Scheme 2).

Scheme 2. Our proposed silylium ion migration dominated hydroamidation mechanism.

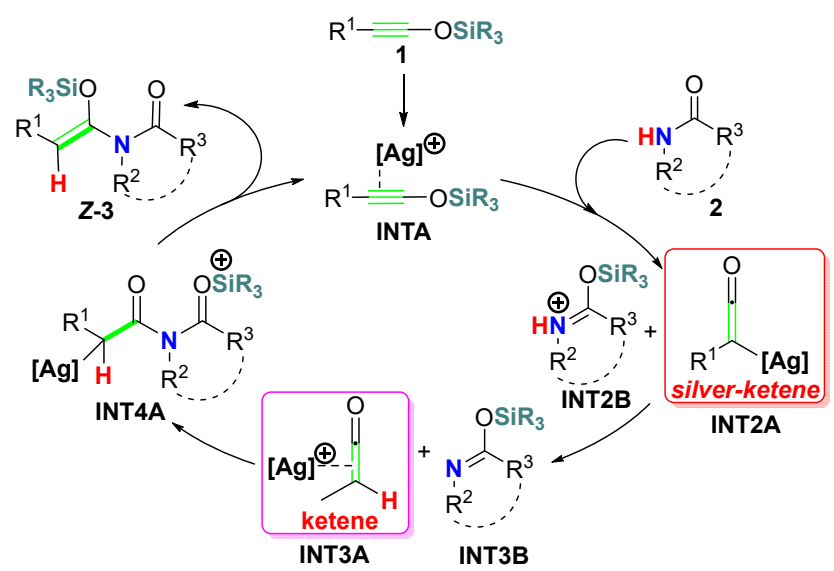

The key feature of the SMH mechanism is Ag+ strong interact with $\mathrm{C} \equiv \mathrm{C}$ bond of siloxy-alkynes and activate $\mathrm{R}_{3} \mathrm{Si}$ group into silylium ion $\mathrm{SiR}_{3}+$ through $p$ - $\pi$ conjugate effect. $S_{N} 2$ nucleophilic attack of $\mathbf{2}$ at silicon atom of siloxy-alkyne is the initial step of the SMH mechanism. We divide the SMH mechanism into two parts for convenient, the first part (part I) is Ag+ induced $\mathrm{SiR}_{3}+$ and proton exchange between siloxy-alkyne $\mathbf{1}$ and amide 2, which lead to AgNTf coordinated ketene INT3A and silyl-imine INT3B; the second part (part II) is nucleophilic addition between INT3A and INT3B to form INT4A, following with a silylium migration afford final product $\boldsymbol{Z}-\mathbf{3}$ (Scheme 2). By its nature, this is an $\mathrm{Ag}+$ and $\mathrm{SiR}_{3}+$ exchange process, which have emerged as useful catalytic method, especially for unique transformations hardly accessible to Lewis acid $22-23$.

\subsection{Formation of ketene and silyl-imines.}

Complexation of $\mathrm{AgNTf}_{2}$ with 1a makes silicon atom of TIPS group susceptible to $\mathrm{S}_{N} 2$ nucleophilic attack by carbamate 2a. The barrier of this process (TS1) is only 18.3 $\mathrm{kcal} / \mathrm{mol}$ (figure 2). Unlike common $\mathrm{S}_{N} 2$ reaction in organic chemistry, this process leads to five coordinated silicon complex INT1, which then dissociate into silver-ketene INT2a and TIPS $^{+}$coordinated carbamate INT2b. The relatively large size and the $d$-orbital of silicon atom contributed the $\mathrm{S}_{N} 2$ process ${ }^{34-35}$. The strong interaction between $\mathrm{Ag}+$ and $\pi$-bond make silver-ketene INT2a a very good leaving group which also promoted this process ${ }^{22}$.

Formation of INT2a convert initial siloxy-alkynes 1a into a strong nucleophile ${ }^{33}$, the nucleophile index $N_{1 \mathrm{a}}=3.2$, while the nucleophile index $N_{\text {int2a }}=7.2$. Polarity inversion of $\mathbf{1 a}$ take place in this process. The electron transferred from the hydrogen atom of carbamate $\mathbf{2 a}$ into $\mathrm{C}-\mathrm{Ag}$ bond of the INT2a. NBO charge distributions shows that the natural charge of C-Ag changed from $044 \mathrm{e}$ to $-0.16 \mathrm{e}$ from INTa to INT2a, and the natural charge of hydrogen in the carbamate 2a changed from $0.16 \mathrm{e}$ to $0.46 \mathrm{e}$. In the INT2b the hydrogen atom of the nitrogen atom has been activated into proton by TIPS+. 
(a)
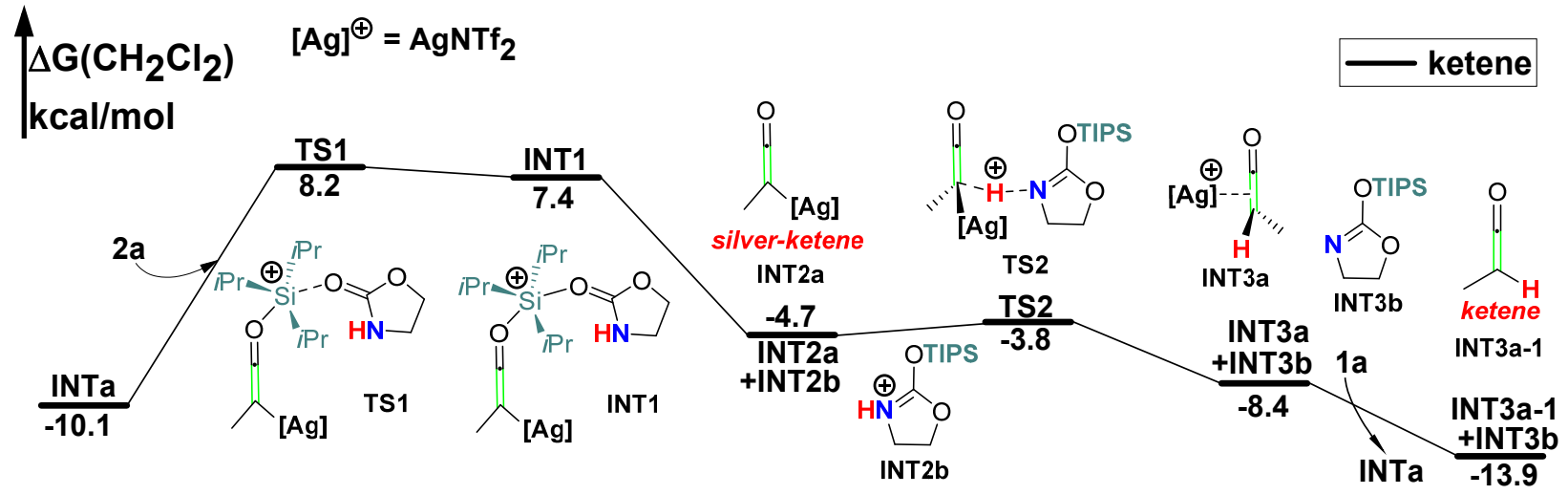

(b)
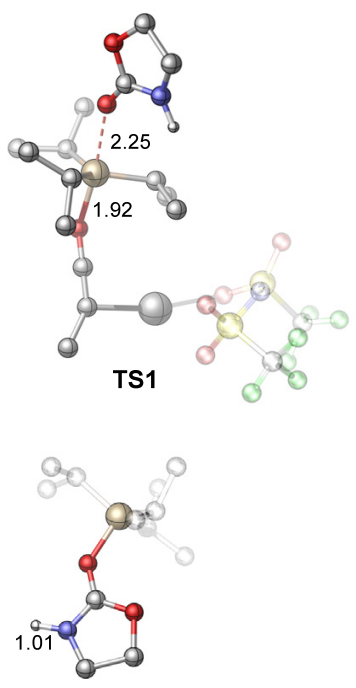

INT2b
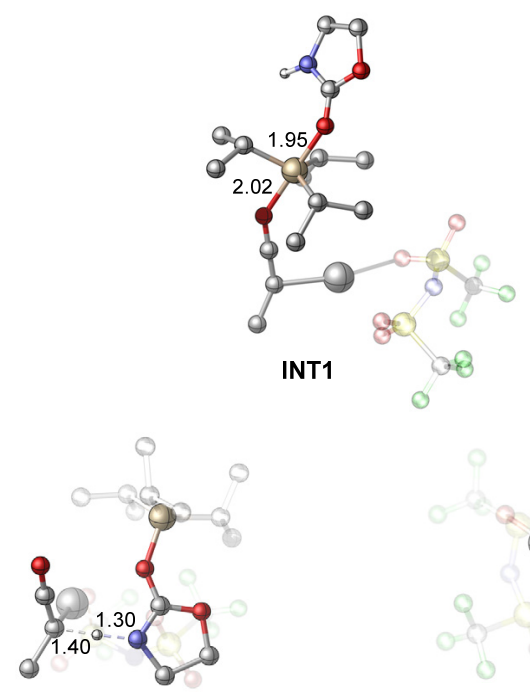

TS2

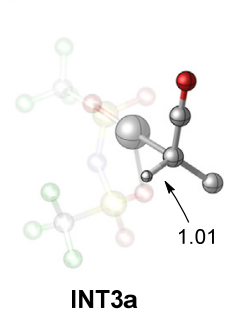

- $\mathbf{H}$

- C

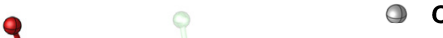

- $\mathbf{N}$

o

Si

$\mathrm{Ag}$

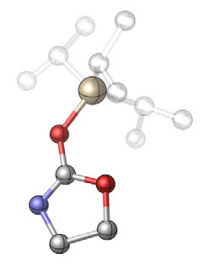

INT3b

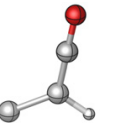

INT3a-1

Figure 2. formation ketene INT3a-1 and silyl-imines INT3b. Gibbs energies are in kcal/mol. a. Gibbs free energy profile. b. Optimized geometries. The hydrogen atom was omitted, and $\mathrm{NTf}_{2}$ - anion was set to transparent for clarity. Except TS1 and INT1, the isopropyl of triisopropylsilyl (TIPS) group was set to transparent for clarity.

Our previous work has shown that Ag+ can activate TIPS group into TIPS+ through $p-\pi$ conjugation. In this reaction Ag+ activate TIPS into TIPS+, TIPS+ then activate the hydrogen atom into proton through $p$ - $\pi$ conjugation, the net effect is Ag+ activate hydrogen atom into proton, which can be regarded as a $\pi$-acid and $\sigma$-acid exchange scheme.

The proton transfer between the INT2 $\mathbf{b}$ and C-Ag bond of INT2a is energetically highly feasible with a barrier (TS2) only $0.9 \mathrm{kcal} / \mathrm{mol}$, leading to silyl-imine INT3b and AgNTf $_{2}$ coordinated ketene INT3a. The electron transferred from electron-rich C-Ag bond into proton in this process, NBO charge distribution shows that the natural charge of $\mathrm{C}-\mathrm{Ag}$ changed from $-0.16 \mathrm{e}$ to $0.11 \mathrm{e}$, and natural charge of hydrogen atom changed from $0.46 \mathrm{e}$ to $0.30 \mathrm{e}$. The net effect of this reaction is the $\mathrm{AgNTf}_{2}$ promoted proton and TIPS+ exchange between siloxy-alkyne $\mathbf{1 a}$ and carbamate $\mathbf{2 a}$ to form ketene INT3a-1 and silyl-imine INT3b. Ketene INT3a$\mathbf{1}$ and silyl-imine INT3b is energetically $2.8 \mathrm{kcal} / \mathrm{mol}$ more stable than siloxy-alkyne $\mathbf{1 a}$ and carbamate $\mathbf{2 a}$.

\subsection{Silylium ion Migration leads to final product.}

Hydroamination or hydroamidation of allenes is quite easy for high activity of the two cumulated $\pi$-bond ${ }^{1,12,21}$ Ketene is analogs of allenes, it's very important intermediate in the organic chemistry ${ }^{36-39}$. Transition metal promoted nucleophilic attack favors take place in the intersection point of the two $\pi$-bond. The barrier (TS3) of $\mathrm{C}-\mathrm{N}$ formation leads to INT4a is only $8.8 \mathrm{kcal} / \mathrm{mol}$. The nucleophilicity of INT3b is higher than 2a (the nucleophilicity $N$-index of imide $N_{\text {int3b }}=2.81$, while $N_{2 \mathrm{a}}=$ 1.86), which contributed to this process. The electron transferred from $\mathrm{Si}-\mathrm{O}$ to $\mathrm{Ag}-\mathrm{C}$ in this process. NBO charge distribution shows that the national charge of $\mathrm{C}$-Ag changed from 0.01 e to $-0.14 \mathrm{e}$, and the natural charge of Si-O changed from $1.22 \mathrm{e}$ to $1.32 \mathrm{e}$. The bond length of $\mathrm{Si}-\mathrm{O}$ changed from $1.72 \AA$ to $1.79 \AA$ (Figure $3 \mathrm{~b}$ ), which implies the bond between silicon and oxygen is weakened. Actually, the migration of 
(a)

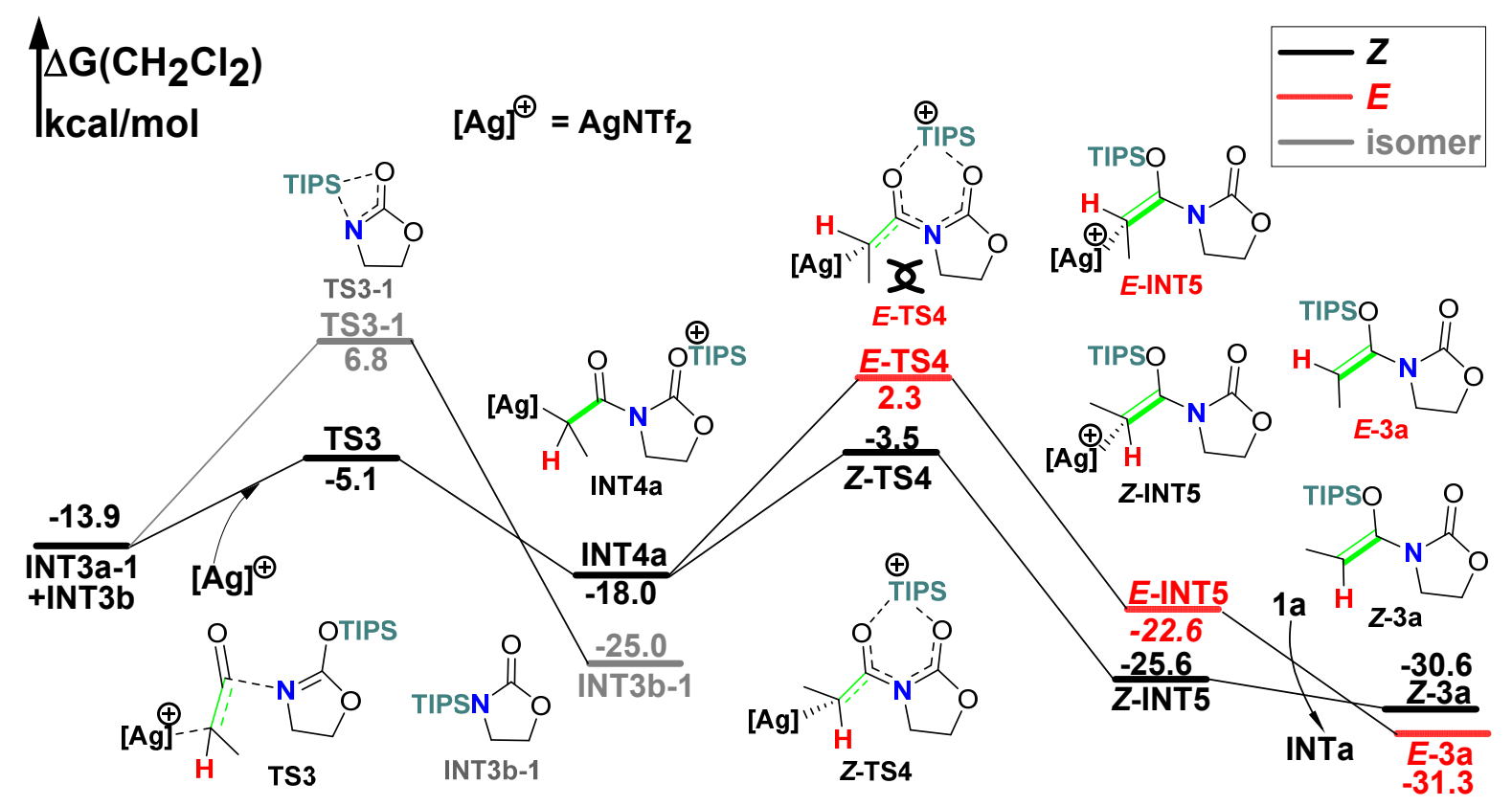

(b)

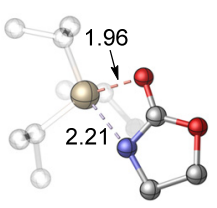

TS3-1

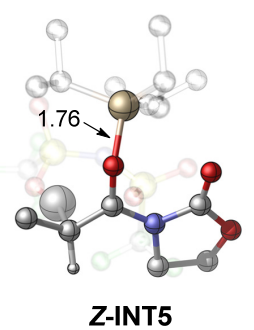

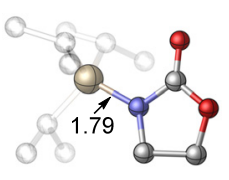

INT3b-1

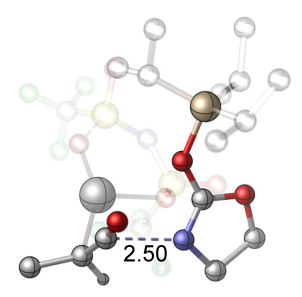

TS3

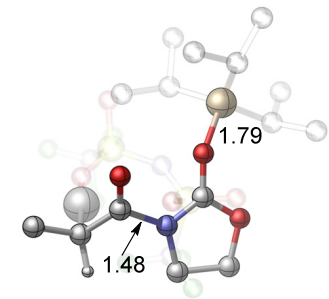

INT4a

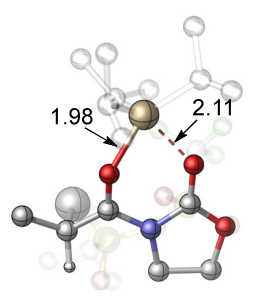

Z-TS4

- H

( $\mathbf{C}$

- $\mathbf{N}$

- 0

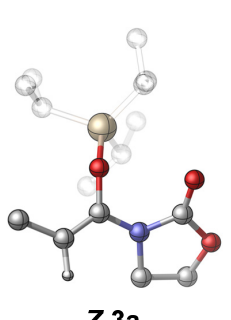

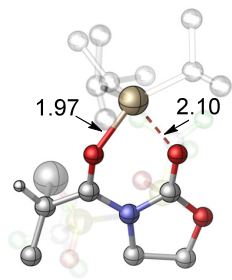

E-TS4

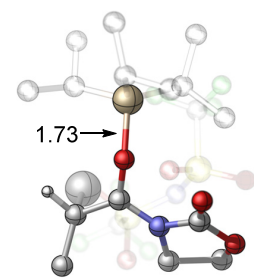

E-INT5

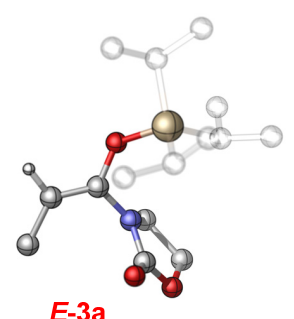

Figure 3. (a) Reaction profiles of formation final product $Z$-3a. Gibbs free energies are in $\mathrm{kcal} / \mathrm{mol}$. (b) Optimized geometries, the hydrogen atom was omitted, $\mathrm{NTf}_{\mathrm{z}^{-}}$anion and the isopropyl of triisopropylsilyl (TIPS) group was set to transparent for clarity.

TIPS group to obtain AgNTf 2 coordinated product $Z$-INT5 is quite easy with a barrier (Z-TS4) only $14.5 \mathrm{kcal} / \mathrm{mol}$. In the $Z$-TS4 the two carbonyl group are almost in the same plane, and the five $p$-orbitals constitute a large $\pi$-delocalized system which lowers the TIPS transfer barrier. After formation of $\boldsymbol{Z}$-int5, electron transferred from $\mathrm{C}$-Ag to Si-O. NBO charge distributions show that the natural charge of $\mathrm{C}$ Ag change from $-0.14 \mathrm{e}$ to $0.04 \mathrm{e}$ and $\mathrm{Si}-0$ change from $1.32 \mathrm{e}$ to $1.26 \mathrm{e}$. The TIPS migration leads to trans-hydroamidation product $\boldsymbol{E}$-3a is relatively energetically disfavored, the barrier (E-TS4) of this step is $5.8 \mathrm{kcal} / \mathrm{mol}$ higher than $\boldsymbol{Z}$ TS4, which is mainly caused by the relatively larger size of methyl group. The transition states (Z-TS4 and $\boldsymbol{E}$-TS4) of the TIPS migration step favor planar configuration and form a big delocalized $\pi$-system, which increase the repulsion between methyl and methylene. Noncovalent interaction (NCI) analysis ${ }^{30}$ was performed to analyze the repulsion between the methyl and methylene groups in the $\boldsymbol{E}$-TS4, as indicated in the Figure 4, there is a large red area between the two groups, while in the $\boldsymbol{Z}$-TS4 the red area is much smaller, indicating a more pronounced steric effect in the $\boldsymbol{E}$ TS4.

Our calculation is excellent in accordance with experimental observations. Kozmin et al. claimed that the ynamides and simple internal alkynes are unreactive in the same conditions. This is a strong support of our proposed SMH mechanism, which highlight the importance of the silylium ion Migration. Ynamides is electron richer than 
siloxy-alkyne, if this reaction take place through the author proposed NUA mechanism, the ynamides should be more reactive. Furthermore, using deuterated amide $\mathbf{2 a}$, no primary deuterium isotope effect $\left(\mathrm{k}_{\mathrm{H}} / \mathrm{k}_{\mathrm{D}}=1.03\right)$ was observed, which means that hydrogen migration is not the rate determine step. Our calculations shows that silylium ion migration (TS1) is the rate determine step in this reaction, if we reduce the size of silyl group, the reaction rate may be accelerated.

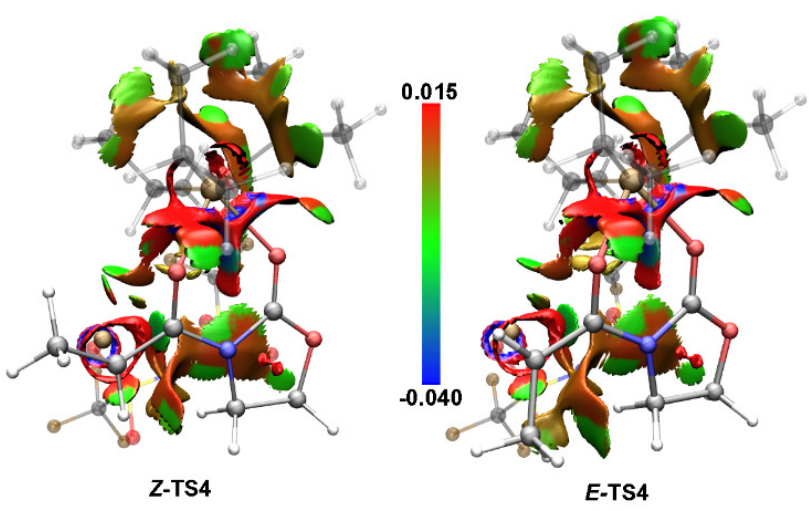

Figure 4. Noncovalent interaction (NCI) analysis of origins of cis-selectivity (red, strong repulsion; green, weak attraction; blue, strong attraction).

\subsection{A general way to synthesis substituted enamides.}

This reaction goes through relatively independent two steps. In the first step, AgNTf 2 convert siloxy-alkyne $\mathbf{1}$ and amide 2 into ketene INT3A-1 and silyl-imine INT3B (scheme 2). In the second step, $\mathrm{AgNTf}_{2}$ promote nucleophilic addition between ketene INT3A-1 and silylimine INT3B, following with a silylium ion migration to afford final product. If the hydrogen atom of ketene was changed into halogen or other groups, this reaction may also take place, and the regio-selective is steric-controlled (scheme 3a). Synthesizing substituted-ketenes has been extensively studied ${ }^{36-38}$, and silyl-imines can be easily obtained (One of the feasible approaches is reaction between Chlorotriisopropylsilane (CITIPS) and amide with base as catalyst in low temperature). So, our calculation provides a general approach to obtain substituted enamides (Scheme 3). Note that the barrier of INT3b tautomerize into INT3b-1 through intramolecular TIPS migration is only $22.8 \mathrm{kcal} / \mathrm{mol}$ (figure 3a, with INT4a as reference point), once the thermodynamically more stable INT3b-1 is formed, the barrier of reverse reaction lead to INT3b is as high as $31.8 \mathrm{kcal} / \mathrm{mol}$, which means that the smallest substituent R7 of ketene A-INT3A-1 should not be too large to ensure formation of $\mathbf{Z}-\mathbf{A}-\mathbf{3}$ is kinetically more favored (Scheme 3a). In the Z-TS4 and $\boldsymbol{E}$-TS4 (figure 3), the movement of methylene of $\mathbf{2 a}$ is constrained by fivemembered ring, which also increase steric effect, the noncyclic silyl-imine may be better tolerated in this rection.

This method could also be used to obtain the two amino (or acylamino) group substituted alkynes $\mathbf{Z}$-B-3 with ketene imines B-INT3A-1 and silyl-imine INT3B as substrates (scheme $3 \mathrm{~b}$ ). The regio-selectivity get rather complicate. In this case, the steric-effect of R7 and R2, and steric effect of
R6 and R4 together determine the $\Delta G$ of cis-configuration transition state $\boldsymbol{Z}$-B-TS4. Similarly, steric effect between R6 and R2, and steric effect between R7 and R4 together determines the $\Delta G$ of the trans-configuration transition state $\boldsymbol{E}$-B-TS4. Our calculations reveal that when $\mathrm{N}$-acetylsubstituted ketene imines B-int3a-1 and TMS-substituted imine TMS-INT3b is used as model substrate, the regioselectivity is reduced compared with previous example (cisselectivity vs trans-selectivity $=9.0 \mathrm{kcal} / \mathrm{mol}$ vs 11.4 $\mathrm{kcal} / \mathrm{mol}$, see details in SI, figure S1).

In the reactions we have studied in the Scheme 3 , silylgroup of INT3B was activated into silylium ion through $p-\pi$ conjugate effect. So, the substrates contain such $p-\pi$ conjugation segment may be also suitable for this reaction (Scheme 3c). We choose silyl-1,2-diazole C-INT3b as model to verify this speculate (see details in Figure S2). Our calculations shows that $\mathbf{C}$-INT3b can react with ketene INT3A-1 to afford desired product with a rate determine barrier only $10.6 \mathrm{kcal} / \mathrm{mol}$ (see details in SI, Figure S2).

\section{Scheme 3. Methods to obtain substituted enamides.}

(a)

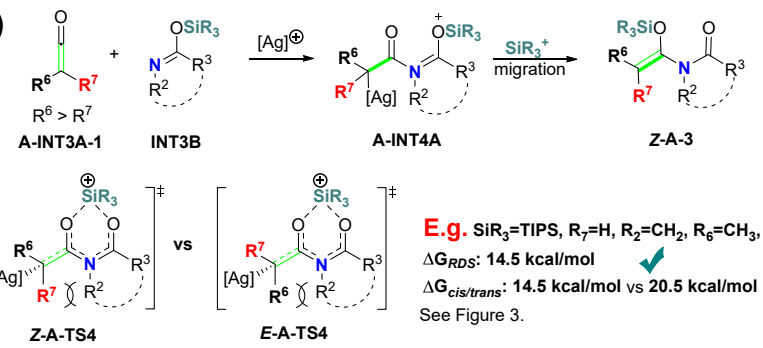

(b)

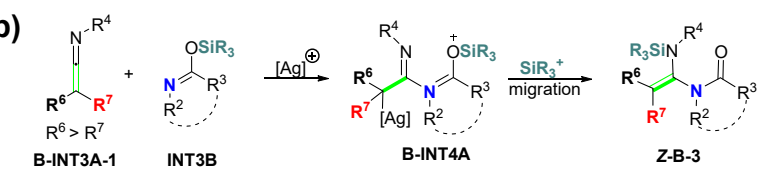

(c)

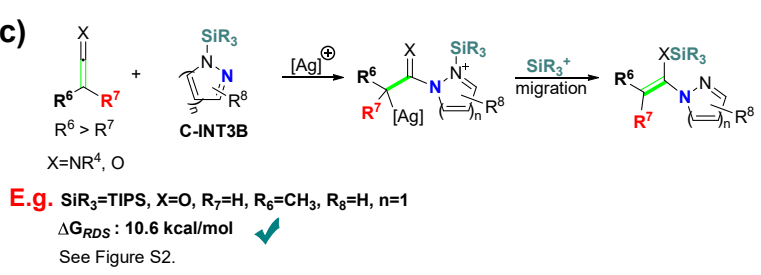

\subsection{Substrate scopes of SMH pathway.}

According to our proposed SMH mechanism, there are rooms to expand scopes of alkynes. For example, if we change siloxy-alkyne into $N$-silyl protected ynamide (or ynamine) B-1, this reaction may also take place (Scheme $4 a$ ). We use carbamate 2a and $N$-TMS substituted ynamide BTMS-1 as model to clarify this point of view (see details in SI, Figure S3), our calculations shows that the hydroamidation of B-TMS-1 through SMH pathway is quite easy with a rate determine barrier (RDB) only 18.0 $\mathrm{kcal} / \mathrm{mol}$. 
Scheme 4. Possible scopes of alkynes and $p$ - $\pi$ conjugation system.

(a)

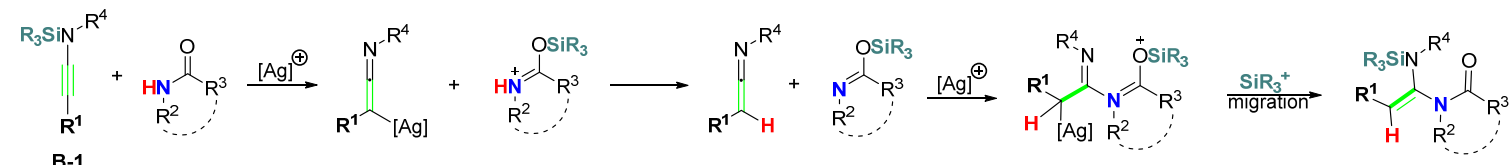
B-1

E.g. $\mathrm{SiR}_{3}=\mathrm{TMS}, \mathrm{R}_{1}=\mathrm{CH} 3, \mathrm{R}_{2}=\mathrm{CH}_{2}, \mathrm{R} 3=-\mathrm{CH}_{2}-\mathrm{CH}_{2}-\mathrm{R}_{4}=\mathrm{COCH}_{3}$ $\Delta \mathrm{G}_{R D S}: 18.0 \mathrm{kcal} / \mathrm{mol} \quad \Delta \mathrm{G}_{\text {cis } / \mathrm{rans}}: 9.0 \mathrm{kcal} / \mathrm{mol} \mathrm{vs} 11.4 \mathrm{kcal} / \mathrm{mol}$ See Figure S3.

(b) $\mathrm{SiR}_{3}=$ TIPS, $\mathrm{R}_{1}=\mathrm{CH}_{3}, \mathrm{R}_{2}=\mathrm{CH}_{2}, \mathrm{R} 3=-\mathrm{CH}_{2}-\mathrm{CH}_{2}-, \mathrm{R}_{4}=\mathrm{COCH}_{3}$ $\Delta \mathrm{G}_{R D S}: 25.8 \mathrm{kcal} / \mathrm{mol}$

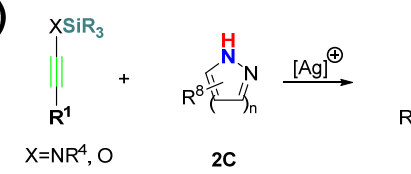<smiles>[X]C([R])=[C]C([R])[Al]</smiles>

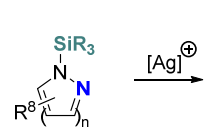

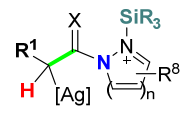
$\underset{\text { migration }}{\stackrel{\mathrm{SiR}_{3}{ }^{+}}{\longrightarrow}}$ $\left.\right|_{H} ^{\mathrm{S}^{\mathrm{SiR}}{ }_{3}} \mathrm{~N}_{\mathrm{n}}^{\mathrm{N}} \mathrm{R}^{8}$

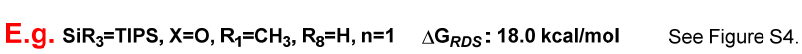

(c)

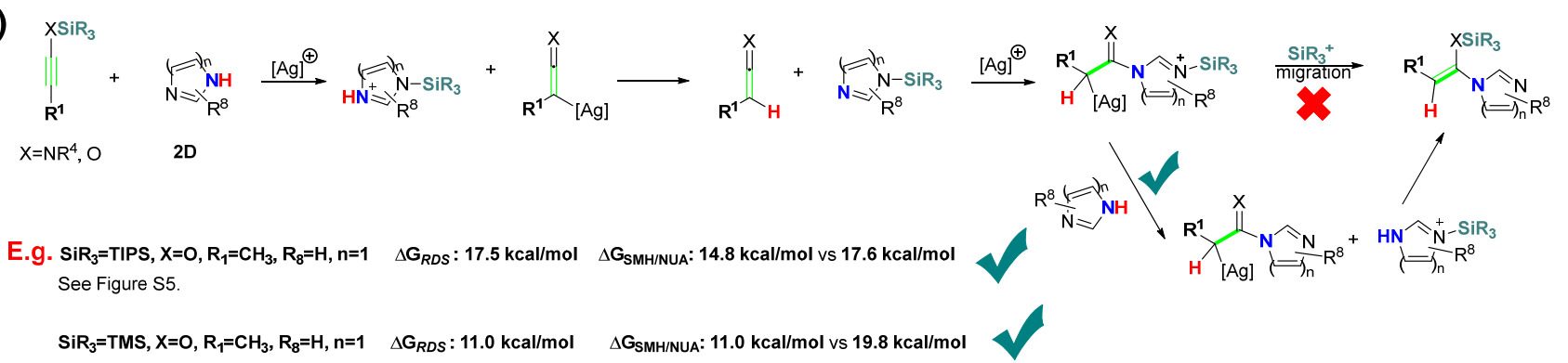

Hydroamidation of B-1 is very sensitive to the volume of silyl group, when use TIPS substituted ynamide B-TIPS-1, this reaction does not take place for the relatively high barrier of silylium ion migration step $(25.8 \mathrm{kcal} / \mathrm{mol}$, Scheme 4a), which is mainly caused by steric effect between TIPS and -acetyl. Due to higher barrier of silylium ion migration step, the isomerization of INT3b occurs preferentially $(22.8 \mathrm{kcal} / \mathrm{mol}$ vs $25.8 \mathrm{kcal} / \mathrm{mol})$.

In our proposed SMH pathway, hydrogen atom of amide 2 was activated into silylium ion through $p-\pi$ conjugate effect, which implies that some cyclic- $p-\pi$ conjugation system, such as diazoles, triazoles, $1 \mathrm{H}-1,2$-diazepine, $1 \mathrm{H}-$ 1,3-diazepine and so on, may also be suitable substrates for this reaction (see Scheme $4 \mathrm{~b}$ and Scheme $4 \mathrm{c}$ ). For example, hydroamination of siloxy-alkyne $\mathbf{1 a}$ with 1,2-diazole is quite easy with a rate-determine barrier $18.0 \mathrm{kcal} / \mathrm{mol}$ (see details in SI, Figure S4). As for 1,3-diazoles, the silylium ion migration of last step take place through $\mathrm{S}_{N} 2$ pathway, with a rate determine barrier $18.0 \mathrm{kcal} / \mathrm{mol}$ (see details in SI, Figure S5). The NUA process can be eliminated by reduce the volume of $\mathrm{SiR}_{3}$ group (Scheme 4c).

\section{Conclusion}

Catalyzed hydroamidation of internal alkynes meet limited success yet. Our proposed SMH pathway provides a different perspective to catalyze hydroamidation of siloxyalkynes, $N$-silyl-protected ynamides or $N$-silyl-protected ynamines. Our proposed SMH mechanism can be divided into two steps, the first step is Ag+ promoted proton and silylium ion (TIPS ${ }^{+}$) exchange between siloxy-alkyne and amide, which lead to ketene and silyl-imine, the second step is Ag+ catalyzed nucleophilic addition between ketene and silyl-imine, following with a silylium ion migration lead to final product. The hydroamidation of $N$-silyl-protected ynamines or $N$-silyl-protected ynamides could be completed through a similar pathway. The protocol of synthesis of ketene (or ketene imines) and silyl-imine have been well documented, which means we can use Ag+ to catalyze ketene (or ketene imines) and silyl-imine to obtain a variety of substituted enamides. The substrate scopes of $N$-H source may not only be limited in amides, other $p$ - $\pi$ conjugated system such as 1,2-diazoles, 1,3-diazoles and diazepines may also suitable for this reaction. In SMH pathway, the electron extraction competition between $\mathrm{Ag}+$ and silylium ion (TIPS+) induce every elementary step and lead to final product, which is an important supplement to the silylium ion chemistry.

\section{ASSOCIATED CONTENT}

\section{Supporting Information.}

This material is available free of charge via the Internet at http://pubs.acs.org."

\section{AUTHOR INFORMATION}

Corresponding Author

*fanhj@dicp.ac.cn

ORCID

Hengding Wang: 0000-0003-4198-6032

HongjunFan: 0000-0003-3406-6932

Notes

The authors declare no competing financial interest. 


\section{ACKNOWLEDGMENT}

Financial support from National Key Research and Development Program of China (No. 2016YFB0600301), National Natural Science Foundation of China (21673224, 21873096), Chinese Academy of Sciences (XDB17010200).

\section{ABBREVIATIONS}

$\mathrm{SMH}$, silylium ion migration mediated hydroamidation; NUA: silver induced nucleophilic addition mechanism

\section{Reference}

1. Huang, L.; Arndt, M.; Gooßen, K.; Heydt, H.; Gooßen, L. J., Late Transition Metal-Catalyzed Hydroamination and Hydroamidation. Chem. Rev. 2015, 115 (7), 2596-2697.

2. Goossen, L. J.; Blanchot, M.; Salih, K. S. M.; Goosen, K., Ruthenium-Catalyzed Addition of Primary Amides to Alkynes: A Stereoselective Synthesis of Secondary Enamides. Synthesis-Stuttgart 2009, (13), 2283-2288.

3. Goossen, L. J.; Arndt, M.; Blanchot, M.; Rudolphi, F.; Menges, F.; Niedner-Schatteburg, G., A Practical and Effective Ruthenium Trichloride-Based Protocol for the Regio- and Stereoselective Catalytic Hydroamidation of Terminal Alkynes. Adv. Synth. Catal. 2008, 350 (17), 2701-2707.

4. Goossen, L. J.; Rauhaus, J. E.; Deng, G. J., Ru-catalyzed antimarkovnikov addition of amides to alkynes: A regio- and stereoselective synthesis of enamides. Angewandte ChemieInternational Edition 2005, 44 (26), 4042-4045.

5. Rodriguez, A. L.; Koradin, C.; Dohle, W.; Knochel, P., Versatile indole synthesis by a 5 -endo-dig cyclization mediated by potassium or cesium bases. Angewandte Chemie-International Edition 2000, 39 (14), 2488-+.

6. Rieder, C. L.; Cole, R., Chromatid cohesion during mitosis: lessons from meiosis. J. Cell Sci. 1999, 112 (16), 2607-2613.

7. Tashrifi, Z.; Mohammadi Khanaposhtani, M.; Biglar, M.; Larijani, B.; Mahdavi, M., Recent Advances in Alkyne Hydroamination as a Powerful Tool for the Construction of C-N Bonds. Asian Journal of Organic Chemistry 2020, 9 (7), 969-991.

8. Neto, J. S. S.; Zeni, G., Alkynes and Nitrogen Compounds: Useful Substrates for the Synthesis of Pyrazoles. Chemistry-a European Journa/ 2020, 26 (37), 8175-8189.

9. Hannedouche, J.; Schulz, E., Hydroamination and Hydroaminoalkylation of Alkenes by Group 3-5 Elements: Recent Developments and Comparison with Late Transition Metals. Organometallics 2018, 37 (23), 4313-4326.

10. Sengupta, M.; Das, S.; Islam, S. M.; Bordoloi, A., Heterogeneously Catalysed Hydroamination. Chemcatchem 2021, 13 (4), 1089-1104.

11. Reznichenko, A. L.; Nawara-Hultzsch, A. J.; Hultzsch, K. C., Asymmetric Hydroamination. In Stereoselective Formation of Amines, Li, W.; Zhang, X., Eds. 2014; Vol. 343, pp 191-260.

12. Fukumoto, Y., Catalytic Hydroamination of $\mathrm{C}-\mathrm{C}$ Multiple Bonds. Journal of Synthetic Organic Chemistry Japan 2009, 67 (7), 735-750.

13. Serrano-Becerra, J. M.; Maier, A. F. G.; Gonzalez-Gallardo, S.; Moos, E.; Kaub, C.; Gaffga, M.; Niedner-Schatteburg, G.; Roesky, P. W.; Breher, F.; Paradies, J., Mono- vs. Dinuclear Gold-Catalyzed Intermolecular Hydroamidation. Eur. J. Org. Chem. 2014, 2014 (21), 4515-4522.

14. Wong, V. H. L.; Hor, T. S. A.; Hii, K. K., Silver-catalysed intramolecular hydroamination of alkynes with trichloroacetimidates. Chem. Commun. 2013, 49 (81), 9272-9274.

15. Zhang, X.; Zhou, Y.; Wang, H.; Guo, D.; Ye, D.; Xu, Y.; Jiang, H.; Liu, H., Silver-catalyzed intramolecular hydroamination of alkynes in aqueous media: efficient and regioselective synthesis for fused benzimidazoles. Green Chemistry 2011, 13 (2), 397-405.
16. Monge, D.; Jensen, K. L.; Franke, P. T.; Lykke, L.; Jorgensen, K. A., Asymmetric One-Pot Sequential Organo- and Gold Catalysis for the Enantioselective Synthesis of Dihydropyrrole Derivatives. Chemistry-a European Journa/2010, 16 (31), 9478-9484

17. Kociecka, P.; Czelusniak, I.; Szymanska-Buzar, T., Efficient and Selective Synthesis of E-Vinylamines via Tungsten(0)-Catalyzed Hydroamination of Terminal Alkynes. Adv. Synth. Catal. 2014, 356(16), 3319-3324.

18. Sun, J.; Kozmin, S. A., Silver-catalyzed hydroamination of siloxy alkynes. Angewandte Chemie-International Edition 2006, 45 (30), 4991-4993.

19. Kuai, C.; Wang, L.; Cui, H.; Shen, J.; Feng, Y.; Cui, X., Efficient and Selective Synthesis of (E)-Enamides via Ru(II)-Catalyzed Hydromidation of Internal Alkynes. Acs Catalysis 2016, 6 (1), 186-190. 20. Lyu, X.; Zhang, J.; Kim, D.; Seo, S.; Chang, S., Merging $\mathrm{NiH}$ Catalysis and Inner-Sphere Metal-Nitrenoid Transfer for Hydroamidation of Alkynes. Journal of the American Chemical Society 2021, 143 (15), 5867-5877.

21. Fang, G.; Bi, X., Silver-catalysed reactions of alkynes: recent advances. Chem. Soc. Rev. 2015, 44 (22), 8124-8173.

22. Wang, H.-D.; Fan, H.-J., Silylium ion mediated $2+2$ cycloaddition leads to 4+2 Diels-Alder reaction products. Comm Chem 2020, 3 (1), $126-135$.

23. Turkmen, Y. E.; Montavon, T. J.; Kozmin, S. A.; Rawal, V. H., Silvercatalyzed formal inverse electron-demand Diels-Alder reaction of 1,2diazines and siloxy alkynes. J. Am. Chem. Soc. 2012, 134 (22), 90629065.

24. Haines, B. E.; Sarpong, R.; Musaev, D. G., Generality and Strength of Transition Metal beta-Effects. J. Am. Chem. Soc. 2018, 140 (33) 10612-10618.

25. Frisch, M. J.; Trucks, G. W.; Schlegel, H. B.; Scuseria, G. E.; Robb, M. A.; Cheeseman, J. R.; Scalmani, G.; Barone, V.; Petersson, G. A.; Nakatsuji, H.; Li, X.; Caricato, M.; Marenich, A. V.; Bloino, J.; Janesko, B. G.; Gomperts, R.; Mennucci, B.; Hratchian, H. P.; Ortiz, J. V.; Izmaylov, A. F.; Sonnenberg, J. L.; Williams; Ding, F.; Lipparini, F.; Egidi, F.; Goings, J.; Peng, B.; Petrone, A.; Henderson, T.; Ranasinghe, D.; Zakrzewski, V. G.; Gao, J.; Rega, N.; Zheng, G.; Liang, W.; Hada, M.; Ehara, M.; Toyota, K.; Fukuda, R.; Hasegawa, J.; Ishida, M.; Nakajima, T.; Honda, Y.; Kitao, O.; Nakai, H.; Vreven, T.; Throssell, K.; Montgomery Jr., J. A.; Peralta, J. E.; Ogliaro, F.; Bearpark, M. J.; Heyd, J. J.; Brothers, E. N.; Kudin, K. N.; Staroverov, V. N.; Keith, T. A.; Kobayashi, R.; Normand, J.; Raghavachari, K.; Rendell, A. P.; Burant, J. C.; Iyengar, S. S.; Tomasi, J.; Cossi, M.; Millam, J. M.; Klene, M.; Adamo, C.; Cammi, R.; Ochterski, J. W.; Martin, R. L.; Morokuma, K.; Farkas, O.; Foresman, J. B.; Fox, D. J. Gaussian 16 Rev. C.01, Revision C.01; Gaussian, Inc.: Wallingford, CT, 2016.

26. Chai, J.-D.; Head-Gordon, M., Long-range corrected hybrid density functionals with damped atom-atom dispersion corrections. Phys. Chem. Chem. Phys. 2008, 10 (44), 6615-6620.

27. Weigend, F.; Ahlrichs, R., Balanced basis sets of split valence, triple zeta valence and quadruple zeta valence quality for $\mathrm{H}$ to $\mathrm{Rn}$ : Design and assessment of accuracy. Phys. Chem. Chem. Phys. 2005, 7 (18), 3297-3305.

28. Fukui, K., The path of chemical reactions - the IRC approach. AcC Chem. Res. 1981, 14 (12), 363-368.

29. Legault, C. Y. CYLview, 1.0b, Université de Sherbrooke: 2009.

30. Johnson, E. R.; Keinan, S.; Mori-Sánchez, P.; Contreras-García, J.; Cohen, A. J.; Yang, W., Revealing Noncovalent Interactions. Journal of the American Chemical Society 2010, 132 (18), 6498-6506.

31. Lu, T.; Chen, F., Multiwfn: A multifunctional wavefunction analyzer. J. Comput. Chem. 2012, 33 (5), 580-592.

32. Humphrey, W.; Dalke, A.; Schulten, K., VMD: Visual molecular dynamics. Journal of Molecular Graphics \& Modelling 1996, 14 (1), 33 38.

33. Domingo, L. R.; Rios-Gutierrez, M.; Perez, P., Applications of the 
Conceptual Density Functional Theory Indices to Organic Chemistry Reactivity. Molecules 2016, 21 (6), 748-769.

34. Lee, V. Y., Tricoordinate silyl cations (silylium ions). Russ. Chem. Rev. 2019, 88 (4), 351-369.

35. Mueller, T., Silylium Ions. In Functional Molecular Silicon Compounds 1: Regular Oxidation States, Scheschkewitz, D., Ed. Springer: New York, 2014; Vol. 155, pp 107-162.

36. Huang, L.; Wu, J.; Hu, J.; Bi, Y.; Huang, D., Ketene dithioacetals in organic synthesis. Tetrahedron Lett. 2020, 61 (4), 151363-1513776.

37. Allen, A. D.; Tidwell, T. T., Recent advances in ketene chemistry. Arkivoc 2016, i, 415-490.

38. Allen, A. D.; Tidwell, T. T., Structure and Mechanism in Ketene Chemistry. In Adv. Phys. Org. Chem., Ian H. Williams, N. H. W., Ed. 2014; Vol. 48, pp 229-324.

39. Minnihan, E. C.; Colletti, S. L.; Toste, F. D.; Shen, H. C., Gold(I)Catalyzed regioselective cyclizations of silyl ketene amides and carbamates with alkynes. J. Org. Chem. 2007, 72 (16), 6287-6289. 